\title{
THE INTERVIEW AS PERSUASIVE COMMUNICATION
}

\author{
H. W. Hildebrandt \\ The University of Michigan
}

On the bulletin board over the desk of a BBA student are several letters. They are neatly typed, possess legitimate signatures, and are impeccably written. One problem. They are all letters of declination, rejection. They would make enviable sample inclusions in communication courses.

"To get a job" is the confident statement of BBA and MBA students in their final year. As interview time approaches, queues are orderly for signup for company interviews; suits come out--on the fellows--("The fellows," said one gal, "became handsome overnight."); hair is preened with caliper precision; non-verbal cues are given more than second thought; even the walk is one of assurance. Then the interview. Sometimes rejection is slow in coming, agonizingly slow. Gloom. Disgust. Hatred of the system. Why?

Several of us talked about it. Many factors, students said, contribute to receiving an affimative letter from a company. Or, receiving a letter of declination. To discover what may have been potential problems we spoke with interviewers and interviewees, trying to answer the question, how could business students better prepare prior to an interview?

One response to the above question is the purpose of these statements: create an assignment which seeks to prepare students for one of their more significant communications, the interview with a potential employer. We will view that assignment in four parts: (1) Problems facing students; (2) Goals of the proposed assignment; (3) Procedures within the assignment; and (4) An assessment and evaluation of the assignment.

\section{Problems Facing Students}

Most business school libraries have numerous books and articles pertaining to the interview. Indeed, placement directors are often readily available for consultation, advice, help. Some students take time; others do not. In short, the initial interview is often given little thought and only haphazardly planned out.

The following issues were considered problems, both by students and interviewers:

1. Lack of company knowledge. Such obvious preparation, or the leck of it, by students was more often a concern of the interviewer. Research was lacking. Adequate responses to rather simple interview questions were infrequent. "Or," mused one interviewer, "do the students interview with so many companies they forget where they are?" 
2. Lack of goal orientation. It seems oversimplified to suggest that either a long-range or short-range career objective with a company is a minimum request. Such a thought-out view is particularly needed by an MBA; interviewers are more lenient with BBAs. Yet, such preparation, with some students, is given but little effort, particularly when interviewing vith many companies.

3. Kinds of questions. Consistency of questions from interviev to interviev is not present. Nor should it be so. But, a mumbled monotone to an unthought of question suggests minimum effort. Students felt unsure of their response because they had given little thought to the variety of queries possible. On the other hand, some are unsure when the interviewer gives them a chance to ask questions. Then the lament vas an attitude of having blown some questions as vell as answers.

4. Resume problems. Trenty students can produce twenty different resumes; for that matter so can twenty different interviewers. Yet, an incomplete resume, poorly organized, visually unattractive, omitted references, or flagrant misspellings damage a potentially successful intervier. Or, some students are overly modest about items which should find place in the document, especially in noting those experiences which suggest qualifications for administrative potential.

5. Appearance. An obvious cue in an interview is appearance. With today's more casual dress, some students are only remotely sensitive to the dress norms of companies. The term "casual" can have inferences, visual and auditory, and can vary according to the perceptions of both interviewer and interviewee.

6. Rambling statements. Assessing causes for this communication problem is difficult. Interviewers imply that organized answers suggest prior preparation on either the company, oneself, or the student's area of study. The problcm is particularly vivid in response to the question, "Tell me about yourself." or some other general opening question.

I. Delivery. A monotone delivery is uninspiring. Conversely, the overpowering delivery takes on the form of coming on too strong; the candidnte is so eager for the position that he talks much, listens little. Or, limp monosyllables inadequately support an idea.

8. Truth stretching. This is not an ethical problem, oftentimes. Rather, a student draving inferences from his own insufficient data can end up vith generalizations neither he, in retrospect, nor the interviever at the moment can totally accept.

We do not pretend that the above several issues are the last vord in interview problems. But, it does seem probable that if candidates had some expertise in facing the above eight issues, their chance for personal persuasion in the interview would be improved. 


\section{Assignment Goals}

Based on the above concerns, we prepared a two- to three-period assignment which would bring together oral and vritten communication in preparing for an initial interview. After the assignment is completed, the student should be able to: (1) Realize the importance of research into a company which is interviewing him; (2) Be able to construct an adequate resume; (3) $\mathrm{Be}$ able to respond to questions most often asked, or likely to be asked in an interview; (4) Be able to improve oral delivery and idea organization upon suggestions of peers and instructor; and (5) Be able to understand the verbal and non-verbal cues that affect persuasion.

\section{Assignment Procedure}

The assignment was divided into two parts: background and the specific assignment.

Background. A series of resumes were viewed and discussed. Any text on either oral or written communication is a source of sample resumes, including the conclusion of the AlA Research Study 47, The Employment Interview.

An option not tried by me but by another colleague, was to invite a company recruiter to explain his views on the resume and the entire interview process. What does he look for? What cues predominate in his discussion with candidates? Another option is to video tape an actual interview for critique by the class. There are difficulties, clearly, yet the presentation is of a real situation.

Because our course emphasizes oral communication, there is consistent stress put on organization of ideas; clarity of language; vitality and variety in delivery.

\section{Specific Assignment.}

1. Each nember must prepare a one-page resume, with a transparency of that resume suitable for use with an overhead projector.

2. Each member must prepare a three-minute presentation, to be read as an oral footnote to the resume. The member could weave his presentation around questions such as: What kind of goals do you have in working for this company? Why do you wish to work for a particular company? Why do you feel you have the qualifications necessary for a specific job? That kind of experiences have you had to prepare you for an intended position? Or, what qualifications do you possess which have prepared you for a managerial leadership position? Or, any topic similar to the above around which an oral statement can be built.

The student then delivers his three-minute statement to the entire class while his resume transparency is projected on a screen behind him.

Following the presentation, members of the class and the instructor 
interview the student on either what he has said; what information is included on the resume, or any issue the class wishes to raise. The assignment concludes with the class offering criticisms on the persuasiveness of the presentation; the acceptability of the resume; the delivery of the statement; and the communication of the verbal and non-verbal cues.

A variation to the above was not tried initially, yet suggested by the students: record the statement and interview on video tape. Then the feedback would be peer and the undeviating recording of the video tape machine.

\section{Assessment and Evaluation}

The following at random comments suggest there was more positive than negative feedback on the assignment:

"After preparing before class, appearing in an interview was easy."

"The assignment broke the ice and prepared us to answer questions we should think about before entering an interview."

"Very useful in demanding quick thinking." realistic."

"It provided experience in handling the interview, but not totally

"Great. Opportunity to compare my performance with others and see how vell we all react to interviews."

"Assignment helped me to increase my knowledge about the entire interview process." as a 4.3 .

On a scale of 1 lowest to 5 highest, the class rated the assignment

In summary, the class voted this assignment as one to be included in future sessions. It does seem to prepare them for an interview, one of their most significant communication performances.

If all the letters written in this country in one day were laid endto-end, they would circle the country nine times! In the United States, we write and mail over 2.5 million letters every hour and spend more than $\$ 20$ million on business letters every day. Communicating by mail is indeed a big billion dollar business. If businessmen sharpen up their letter writing skills, they will decrease their company costs and increase profits. While no letter is unimportant, the relationship between sales and profits pinpoints the sales letter as one of the most important you'll ever write. No other type of correspondence brings a greater return on its investment and influences so many people.--Lou Kriloff, president of the Letterpower Institute, and $A B C A$ member. 